\title{
OCT ASSESSMENT OF MACULAR THICKNESS IN NON-PROLIFERATIVE DIABETIC RETINOPATHY IN RELATION TO GLYCOSYLATED HEMOGLOBIN
}

\author{
By
Amr Muhammad Badr Salah El-Deen, Hany Mahmoud Baiomy Sammor and Mohammed Al Taher Abd El-Wahab \\ Ophthalmology Department, Faculty of Medicine, Al-Azhar University \\ Corresponding author: Amr Muhammad Badr Salah El-Deen, \\ E-mail: dramrbadrsalah@gmail.com
}

\begin{abstract}
Background: Diabetic retinopathy (DR), also known as diabetic eye disease, is a retinal damage that occurs due to diabetes. Blindness can be the end result of diabetic retinopathy.

Objective: To evaluate the relation of macular thickness to glycosylated hemoglobin in patients with nonproliferative diabetic retinopathy.

Patients and Methods: This study included 100 eyes of 100 patients with a diagnosis of type 2 DM. This was designed as an observational, cross-sectional and non-cohort study during the period from 6/2019 to 3/2020. One hundred eyes were divided into two equal groups: one group included diabetic patients with no diabetic retinopathy and the other group included diabetic patients with non-proliferative diabetic retinopathy. Patients were recruited from Retinal clinic in Al-Azhar University Hospital and asked to participate in this study.
\end{abstract}

Results: The results showed that non-proliferative diabetic retinopathy (NPDR) group and group of no DR were comparable as regard age, sex and best corrected visual acuity (BCVA). There was a statistically insignificant difference between group of no DR and NPDR group, but group of no DR had shorter duration of DM, lower HbA1c level, lower macular thickness in all of the 9 standard early treatment diabetic retinopathy study (ETDRS) subfields, lower total macular volume (TMV) than NPDR Group. The results showed that central subfield macular thickness (CST) is positively and significantly related to glycosylated hemoglobin (HbA1c) level in each group of no DR and NPDR, and that severity of DR stage was significantly increased with increased HbA1c levels. The results also showed that there's significant positive association between severity of DR stage and macular thickness in all of the nine standard ETDRS subfields. There was a positive significant relation between duration of DM and HbAlc level in type 2 diabetic patients, while there was no significant relation between duration of DM and macular thickness. The results also showed significant inverse relation between insulin use and $\mathrm{HbAlc}$ level, and significant inverse relation between insulin use and prevalence of DR in type 2 diabetic patients.

Conclusion: Increased incidence of DR, increased macular thickness and increased incidence of diabetic macular edema were associated with increased level of glycosylated hemoglobin in type II diabetic patients.

Keywords: Macular Thickness, Non-Proliferative Diabetic Retinopathy, Glycosylated Hemoglobin. 


\section{INTRODUCTION}

Diabetic retinopathy (DR), also known as diabetic eye disease, is a retinal damage that occurs due to diabetes. Blindness can be the end result of diabetic retinopathy (Hooper et al., 2012). Is a progressive disease predominantly affects the integrity of the microscopic vessels found in the retina. DR can be broadly divided into two clinical stages: non-proliferative diabetic retinopathy (NPDR) and proliferative diabetic retinopathy (PDR) (Sohn et al., 2016).

In NPDR, hyperglycemia results in damage of capillaries walls causing microaneurysms that eventually rupture to form dot and blot hemorrhages. The weakened vessels also become leaky causing macular edema. Resolution of fluid can leave behind yellow sediment of lipid byproducts called hard exudates. As NPDR progresses, obstruction of affected vessesls may cause infarction of the nerve fiber layer resulting in fluffy white patches called cotton wool spots (CWS) (Wani et al., 2010).

While the effects of neovascularization in PDR can be devastating, the most common cause of vision loss in diabetics is macular edema. Macular edema can occur in NPDR, but it is more common in more severe cases of DR due to the leakiness of the new blood vessels (Pierro et al., 2010).

It has been estimated that without treatment for PDR, $50 \%$ of all patients will become blind within 5 years following diagnosis. Optical coherence tomography (OCT) gave us the possibility to measure the macular thickness objectively and also the ability to follow the progression of DR quantitatively (Hee et al., 2010).

Long term control of hyperglycemia can be monitored by periodic measurements of glycosylated hemoglobin (HbA1c). Diabetes control and complications trials showed that intensive glycemic control had been proved to be effective in decreasing development and progression of diabetic retinopathy incidence rate in type 1 and type 2 diabetes mellitus (Moon et al., 2011).

The aim of the present work was to evaluate the relation of macular thickness to glycosylated hemoglobin in patients with non-proliferative diabetic retinopathy.

\section{PATIENTS AND METHODS}

This study included 100 eyes of 100 diabetic patients. This study was designed as an observational, cross-sectional and non-cohort study during the period from $6 / 2019$ to $3 / 2020$. Patients were recruited from Retinal clinic in Al-Azhar University Hospital and asked to participate in this study.

\section{Patients were divided into 2 equal} groups: Group A: Diabetic patients without diabetic retinopathy, and Group B: Diabetic patients with non-proliferative diabetic retinopathy.

\section{Inclusion criteria:}

1. Type II diabetic patients without DR.

2. Type II diabetic patients with nonproliferative DR.

\section{Exclusion criteria:}

1. Patients with a history of Type I DM.

2. Proliferative DR. 
3. Ocular diseases (i.e. Pre-existing glaucoma, high myopia, optic nerve pathology, vitreous hemorrhage, dense cataract).

4. Systemic disease (i.e. hypertension)

5. Systemic medication (i.e. Chloroquine, Tamoxifen, Canthaxanthine) to exclude its effect on macular thickness.

6. Previous ocular surgery (retinal surgery, previous laser treatment).

All subjects participating in the study were asked to sign consent before inclusion. Then they were subjected to:

\section{Full Medical history.}

\section{Careful ocular examination on the day of OCT assessment.}

The non-proliferative diabetic retinopathy (NPDR) was diagnosed according to the simplified Early Treatment Diabetic Retinopathy study (ETDRS) severity scale. Mild NPDR was characterized by the presence of a few microaneurysms, moderate NPDR which was characterized by the presence of multiple microaneurysms, dot-and-blot hemorrhages, venous beading, and/or cotton wool spots, severe NPDR which was characterized by the presence of cotton wool spots, venous beading, and severe intraretinal microvascular abnormalities (IRMA). It was diagnosed using the "4-2-1 rule." A diagnosis was made if the patient has any of the following: diffuse intraretinal hemorrhages and microaneurysms in 4 quadrants, venous beading in $\geq 2$ quadrants, or IRMA in $\geq 1$ quadrant.

\section{Investigations:}

- Hemoglobin A1c: Blood sample was taken on the day of OCT assessment to measure HbA1c level.

- OCT macular thickness was performed by a single examiner.

\section{Optical Coherence Tomography (OCT):}

The same examiner performed all OCT measurements. Optical Coherence Tomography (OCT) measurement for macular thickness was performed using the same device using Topcon SD-OCT (3D OCT-2000, version 8.30; Topcon Corporation, Tokyo, Japan). This OCT system has a resolution of $6 \mu \mathrm{m}$. As a light source, it uses super luminescent diodes with a wavelength of $840 \mathrm{~nm}$. And a high speed of 27,000 A-scans per second.

\section{Macular Thickness Measurements:}

After pharmacological pupillary dilation using tropicamide eye drop $1.0 \%$ by putting 1 drop every 5 minutes 3 times, the Patients were asked to fixate on an internal fixation target during the scanning process and if fixation was not central, the external fixation target was used to move the scanning area centrally over the macula.

The 3D macula protocol was used for macular thickness measurements. All scans were taken as close to the fovea as possible, such that the thinnest point of the macula was imaged, so as to avoid errors in the thickness measurements due to slight differences in positioning. OCT scans were segmented automatically by the segmentation algorithms incorporated in the Topcon 3D OCT-2000 software, 
which demarcates the internal limiting membrane (ILM) and the retinal pigment epithelium (RPE) and the retinal thickness map was generated. For each eye, the automatically-registered ETDRS grid over the topographic map was recorded. If the ETDRS grid was not properly placed over the fovea, the grid was manually moved to the correct position. The retinal thickness map was scanned by moving the computer cursor in the macular area and the point with the highest retinal thickness was recorded as maximum retinal thickness (MRT). Scans with a quality factor $<40$ were excluded.

The 3D macula protocol used for macular thickness measurements consisted of a raster-scan composed of $512 \times 128$ axial scans covering an area of $6 \times 6 \mathrm{~mm}$ in the macular region. It reconstructed a color topographic image displayed with numeric averages of thickness measurements for each of the 9 map regions within a $6 \times 6 \mathrm{~mm}$ area centered on the fovea, as defined by the ETDRS. According to ETDRS map, macula was divided into 9 regions with 3 concentric rings measuring $1 \mathrm{~mm}$ (innermost ring), $3 \mathrm{~mm}$ (inner ring) and 6 $\mathrm{mm}$ in diameter (outer ring) centered on the fovea. The innermost $1 \mathrm{~mm}$ ring is the fovea while the $3 \mathrm{~mm}$ inner ring and 6 $\mathrm{mm}$ outer ring are further divided into four equal regions. It identified the layers of the retina and determined macular thickness by measuring the distance between the inner limiting membrane (ILM) and the inner boundary of retinal pigment epithelium.

\section{Statistical Analysis:}

Data were collected, revised, coded and entered to the Statistical Package for the Social Sciences (IBM SPSS) version 23. The quantitative data were presented as mean, standard deviations and ranges when their distribution found parametric. Also qualitative variables were presented as number and percentages. So, the pvalue was considered significant when $\mathrm{P}<$ 0.05. The comparisons between groups with qualitative data were done by using Chi-square test. The comparison between two groups with quantitative data and parametric distribution were done by using Independent t-test. Spearman correlation coefficients were used to assess the correlation between two quantitative parameters in the same group.

\section{RESULTS}

This work included one hundred eyes from 100 patients with a diagnosis of type II DM, the ranged age 30-60 years with mean $54.27 \pm 8.74$ years, while 56 were males and 44 were females, mean duration of DM was $17.67 \pm 6.73$ years, mean HbA1c level was $8.15 \pm 1.42 \%$ and mean corrected visual acuity was $0.83 \pm 0.10$,
$53 \%$ of patients were on oral hypoglycemic agents, $27 \%$ on insulin and $20 \%$ on combination of both insulin and oral hypoglycemic agents, $50 \%$ of patients were without diabetic retinopathy and $50 \%$ with non-proliferative diabetic retinopathy of diabetic retinopathy (Table 1). 
Table (1): Distribution of optical coherence tomography (OCT) cases according to their demographic data regarding gender and age $(n=100)$

\begin{tabular}{|l|c|}
\hline \multicolumn{1}{|c|}{ Demographic data } & Total (n=100) \\
\hline Age (years) & \\
\hline Range & $30-60$ \\
\hline Mean(M) \pm SD & $54.27 \pm 8.74$ \\
\hline Gender & $56(56 \%)$ \\
\hline Male & $44(44 \%)$ \\
\hline Female & $17.67 \pm 6.73$ \\
\hline Duration of DM (years) & $8.15 \pm 1.42$ \\
\hline HbA1c level \% & $0.83 \pm 0.10$ \\
\hline Corrected visual acuity & $237.66 \pm 35.73$ \\
\hline CST ( $\boldsymbol{\mu m})$ & $7.33 \pm 0.68$ \\
\hline Total macular volume (mm $\left.{ }^{3}\right)$ & \\
\hline Sugar control & $53(53 \%)$ \\
\hline Oral hypoglycemic agents & $27(27 \%)$ \\
\hline Insulin & $20(20 \%)$ \\
\hline Combination & \\
\hline Diabetic retinopathy grading & $50(50 \%)$ \\
\hline No diabetic retinopathy & $50(50 \%)$ \\
\hline Non-proliferative diabetic retinopathy & \\
\hline
\end{tabular}

There was no statistically significant difference between the no DR and NPDR groups according to gender. This table shows statistically significant difference between the two groups regarding duration of DM and HbA1c level\% (Table 2).

Table (1): Comparison between group of no DR and NPDR group according to gender, age, duration of $\mathrm{DM}$, Hba1c level \% and corrected visual acuity

\begin{tabular}{|c|c|c|c|c|}
\hline \multirow{2}{*}{ Parameters } & Groups & No DR $(\mathbf{n = 5 0})$ & NPDR $(\mathbf{n = 5 0})$ & p-value \\
\hline \multirow{2}{*}{ Gender } & Male & $30(60.0 \%)$ & $26(52.0 \%)$ & \multirow{2}{*}{$>0.05$} \\
\cline { 2 - 5 } & Female & $20(40.0 \%)$ & $24(48.0 \%)$ & $>0.05$ \\
\hline Age (years) & $54.59 \pm 10.91$ & $56.11 \pm 10.37$ & $<0.001$ \\
\hline Duration of DM (years) & $15.20 \pm 4.19$ & $19.29 \pm 3.80$ & $>0.003$ \\
\hline HbA1c level \% & $7.58 \pm 1.74$ & $8.72 \pm 1.92$ & $>0.05$ \\
\hline Corrected visual acuity & $0.84 \pm 0.12$ & $0.82 \pm 0.08$ & \\
\hline
\end{tabular}

There wasa statistically significant difference between the two groups regarding TMV, average MT and macular thickness of all of the standard 9 ETDRS subfields. This table shows statistically significant difference between the two groups according to HbA1c level \% (Table 3). 
Table (3): Comparison between group of no DR and NPDR group as regard total macular volume (TMV), average MT, central subfield macular thickness (CST), superior inner MT, superior outer MT, temporal inner MT, temporal outer MT, inferior inner MT, inferior outer MT, nasal inner MT, nasal outer MT and HbA1c level \%

\begin{tabular}{|c|c|c|c|c|c|c|}
\hline \multirow{2}{*}{\multicolumn{2}{|c|}{ Variables $\quad$ Groups }} & \multicolumn{2}{|c|}{$\begin{array}{c}\text { NO DR group } \\
(n=50)\end{array}$} & \multicolumn{2}{|c|}{$\begin{array}{l}\text { NPDR group } \\
(n=50)\end{array}$} & \multirow[t]{2}{*}{ p-value } \\
\hline & & Mean & \pm SD & Mean & \pm SD & \\
\hline \multicolumn{2}{|l|}{ TMV $\left(\mathbf{m m}^{3}\right)$} & 7.12 & 0.58 & 7.53 & 0.77 & $<0.004$ \\
\hline \multicolumn{2}{|c|}{ Average MT $(\mu \mathrm{m})$} & 245 & 31.67 & 286 & 52.87 & $<0.001$ \\
\hline \multicolumn{2}{|l|}{$\operatorname{CST}(\mu \mathrm{m})$} & 218.72 & 35.78 & 256.59 & 35.68 & $<0.001$ \\
\hline \multicolumn{2}{|c|}{ Superior inner MT $(\mu \mathrm{m})$} & 264.26 & 47.57 & 321.32 & 57.84 & $<0.001$ \\
\hline \multicolumn{2}{|c|}{ Superior outer MT $(\mu \mathrm{m})$} & 222.22 & 35.56 & 261.26 & 41.80 & $<0.001$ \\
\hline \multicolumn{2}{|c|}{ Temporal inner MT $(\mu \mathrm{m})$} & 249.25 & 37.39 & 309.31 & 46.40 & $<0.001$ \\
\hline \multicolumn{2}{|c|}{ Temporal outer MT (um) } & 205.21 & 43.09 & 261.26 & 54.86 & $<0.001$ \\
\hline \multicolumn{2}{|c|}{ Inferior inner MT $(\mu \mathrm{m})$} & 285.29 & 51.35 & 318.32 & 57.30 & $<0.001$ \\
\hline \multicolumn{2}{|c|}{ inferior outer MT $(\mu \mathrm{m})$} & 245.25 & 39.24 & 254.25 & 40.68 & $>0.05$ \\
\hline \multicolumn{2}{|c|}{ Nasal inner MT $(\mu \mathrm{m})$} & 271.27 & 40.69 & 322.32 & 48.35 & $<0.001$ \\
\hline \multicolumn{2}{|c|}{ nasal outer MT $(\mu \mathrm{m})$} & 252.25 & 52.97 & 272.27 & 57.18 & $>0.05$ \\
\hline \multirow{2}{*}{ HbA1c level \% } & $\leq 8$ & \multicolumn{2}{|c|}{$41(82 \%)$} & \multicolumn{2}{|c|}{$15(30 \%)$} & \multirow{2}{*}{$<0.001$} \\
\hline & $>8$ & \multicolumn{2}{|c|}{$9(18 \%)$} & \multicolumn{2}{|c|}{$35(70 \%)$} & \\
\hline
\end{tabular}

The following figures showed different examples of OCT measurement of macular thickness from both groups of no DR and NPDR:

Figure (1): OCT of a case of no DR showing that CST was $185 \mu \mathrm{m}$, the measured HbA1c was $6.8 \%$ in the same patient
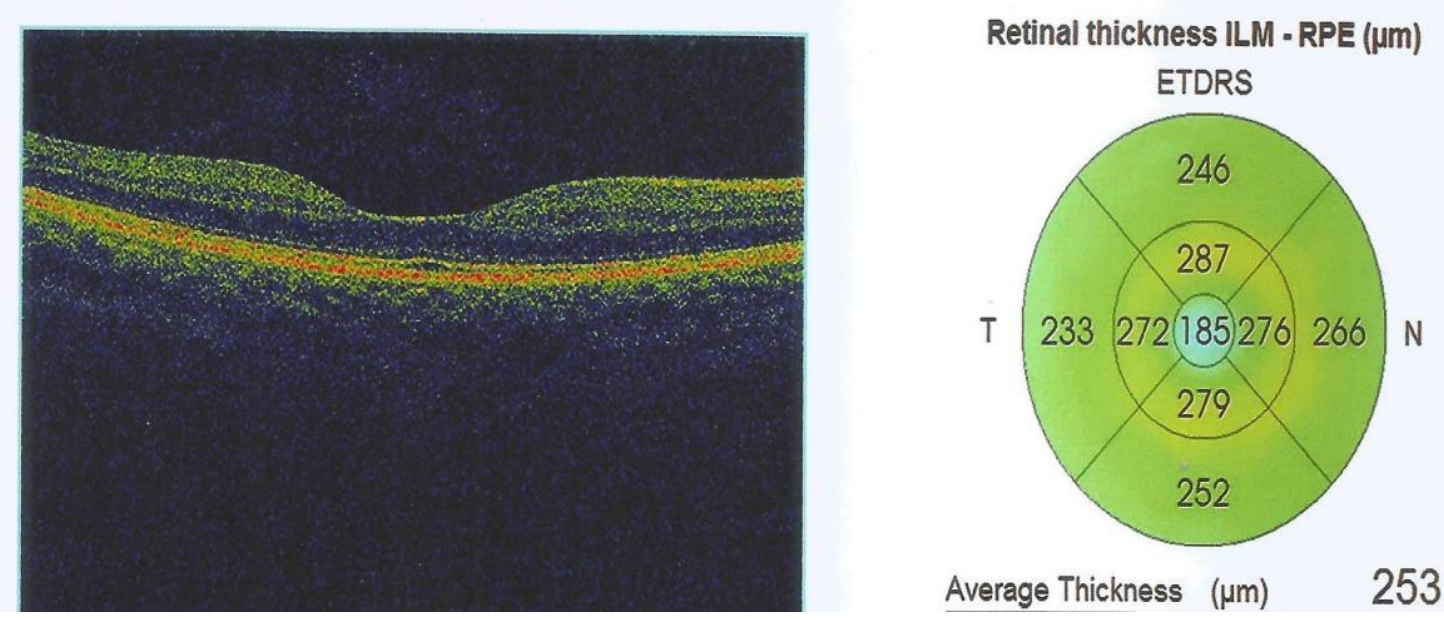
Figure (2): OCT of a case of no DR showing that CST was $195 \mu \mathrm{m}$, the measured HbA1c was $7.0 \%$ in the same patient
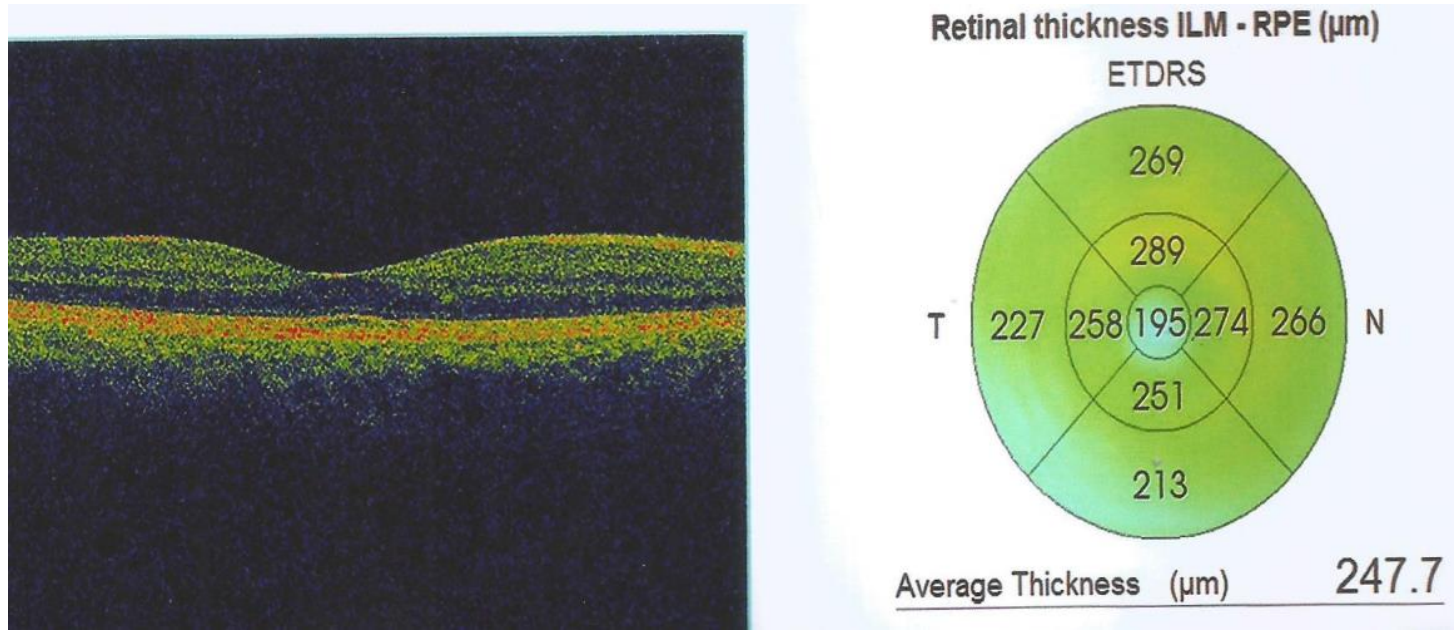

Figure (3): OCT of a case of no DR showing that CST was $212 \mu \mathrm{m}$, the measured HbA1c was $7.5 \%$ in the same patient
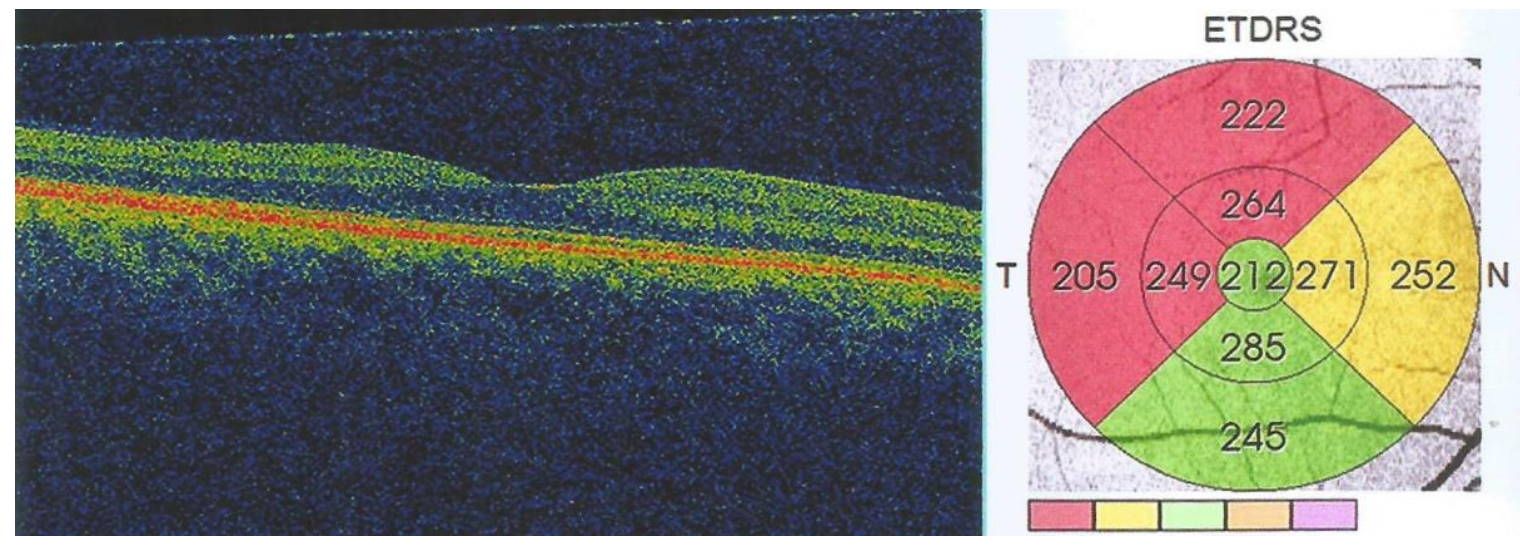

Figure (4): OCT of a case of no DR showing that CST was $228 \mu \mathrm{m}$, the measured HbA1c was $7.8 \%$ in the same patient
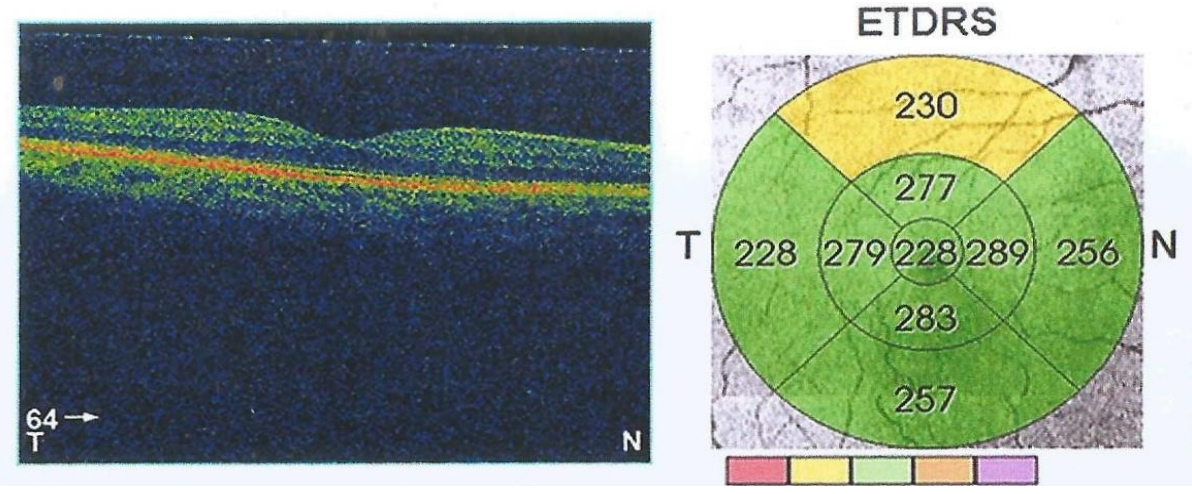
Figure (5): OCT of a case of no DR showing that CST was $263 \mu \mathrm{m}$, the measured HbA1c was $8.8 \%$ in the same patient
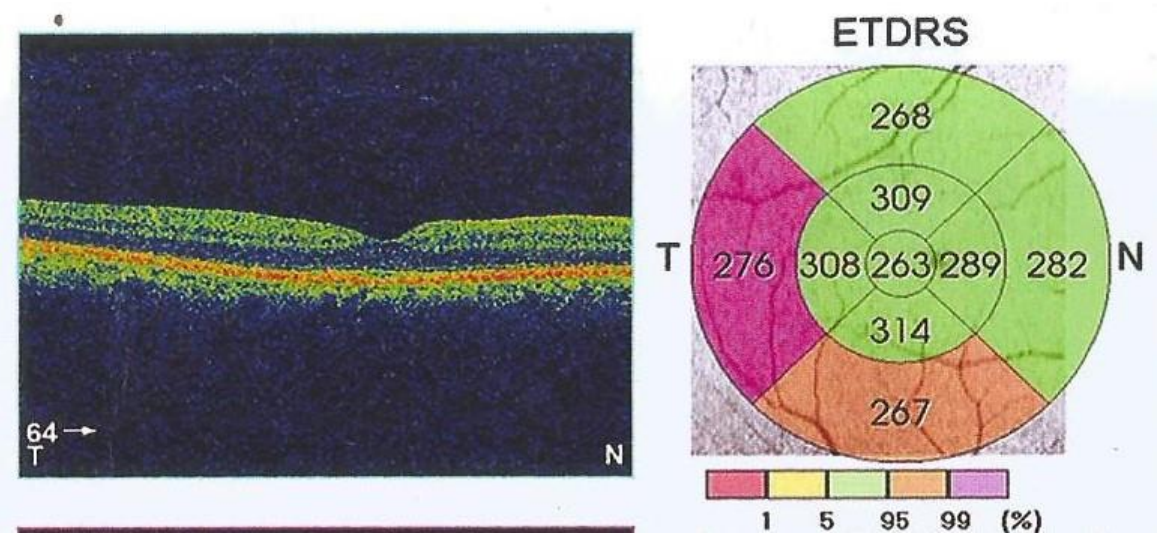

Figure (6): OCT of a case of NPDR showing that CST was $237 \mu \mathrm{m}$, the measured HbA1c was $7.8 \%$ in the same patient
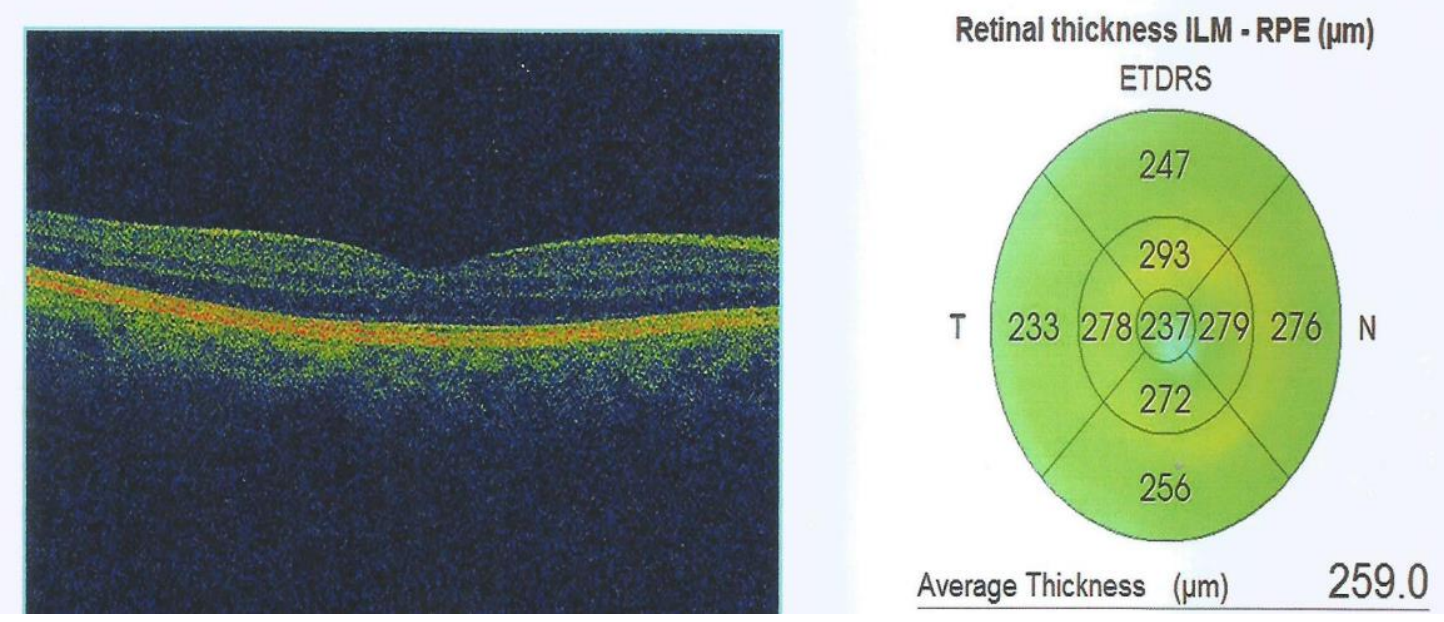

Figure (7): OCT of a case of NPDR showing that CST was $256 \mu \mathrm{m}$, the measured HbA1c was $8.5 \%$ in the same patient
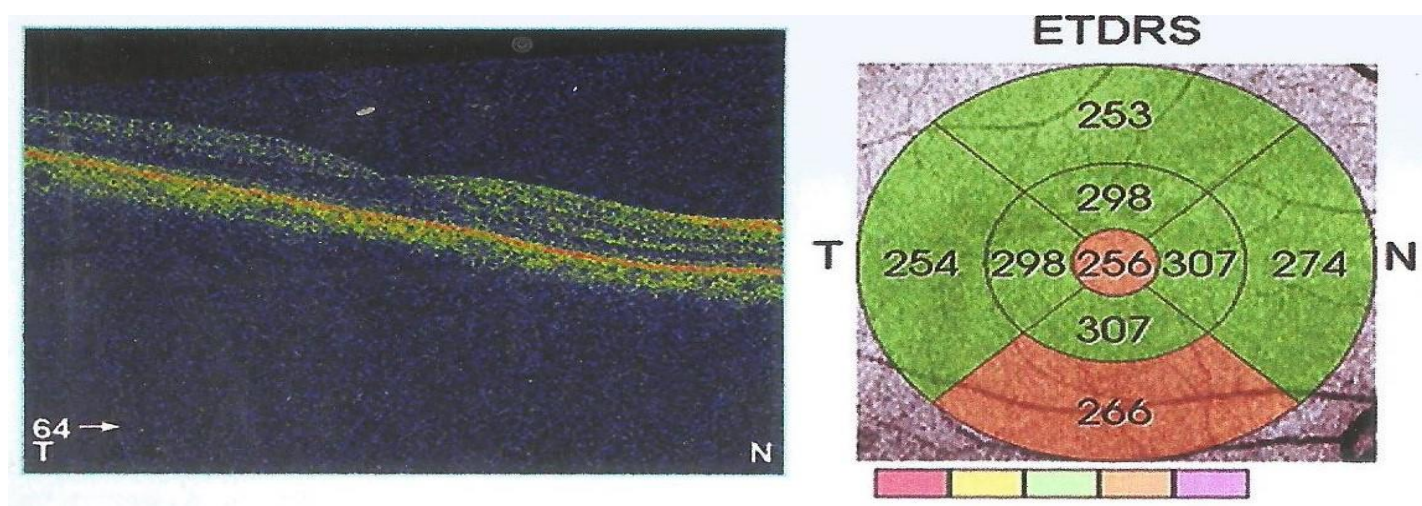
Figure (8): OCT of a case of NPDR showing that CST was $266 \mu \mathrm{m}$, the measured HbA1c was $9 \%$ in the same patient
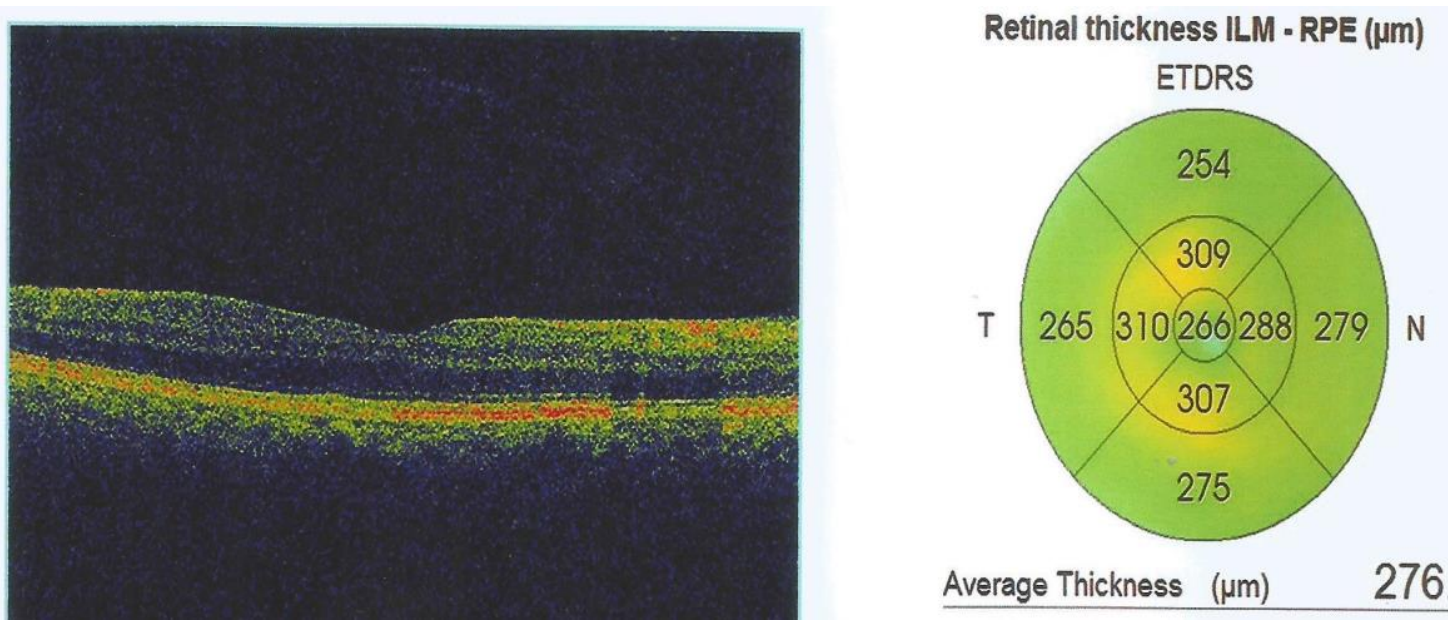

\section{Average Thickness $(\mu \mathrm{m}) \quad 276.1$}

Figure (9): OCT of a case of NPDR showing that CST was $299 \mu \mathrm{m}$, the measured HbA1c was $10 \%$ in the same patient
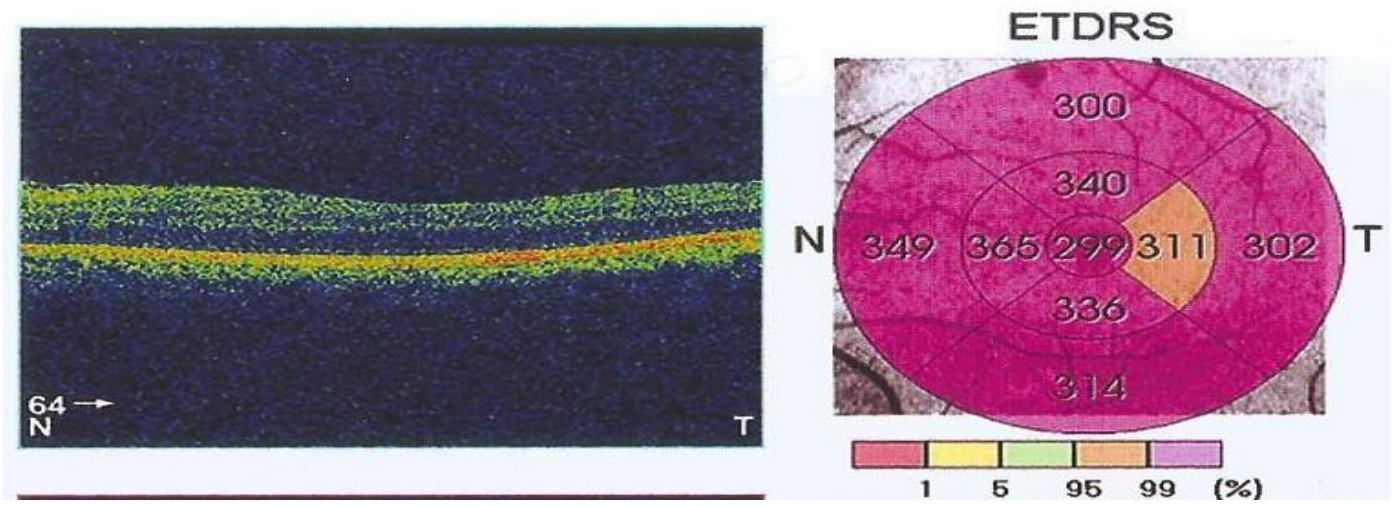

Figure (10): OCT of a case of NPDR showing that CST was $311 \mu \mathrm{m}$, the measured HbA1c was $11 \%$ in the same patient
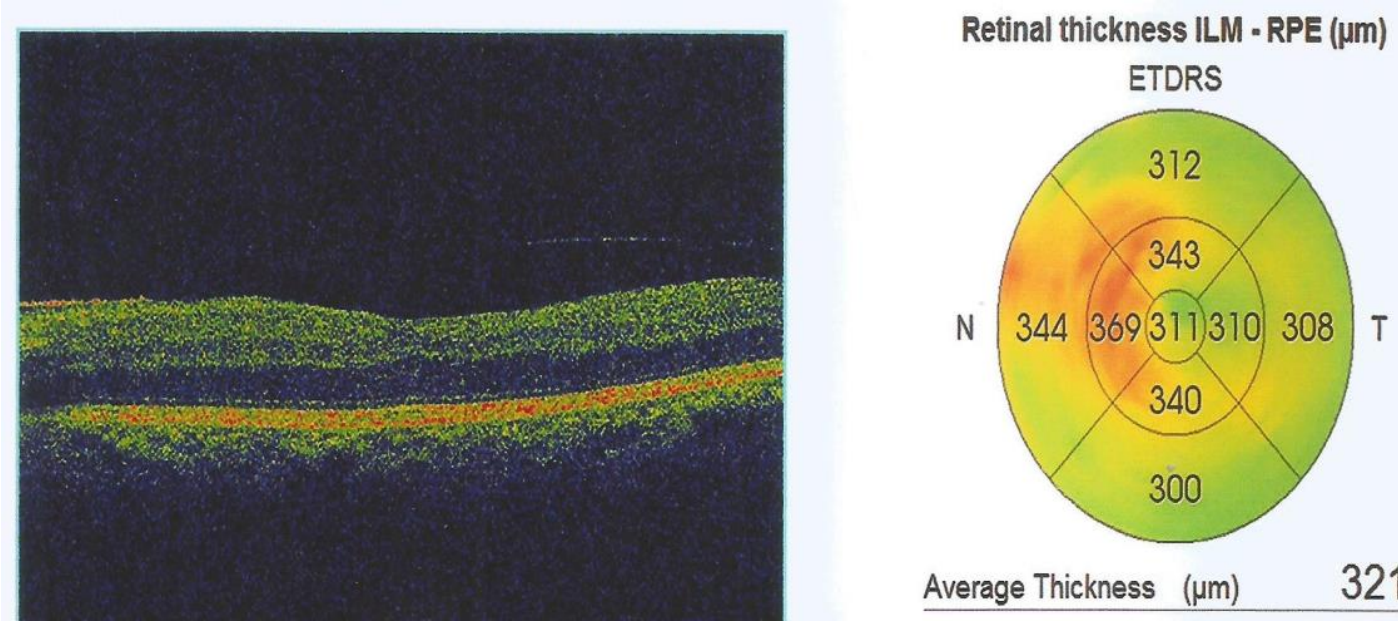

Average Thickness $(\mu \mathrm{m})$

321.3 
There was a statistically significant difference between $\leq 8$ and $>8$ at $\mathrm{HbAlc}$ level \% according to CST in NPDR group (Table 4).

Table (4): Comparison between $\leq 8$ and $>8$ at HbA1c level \% according to CST in the NPDR group $(\mathbf{n}=50)$

\begin{tabular}{|c|c|c|}
\hline HbA1c level \% & No. & CST $(\boldsymbol{\mu m})$ \\
\hline$\leq \mathbf{8}$ & $\mathbf{1 5}$ & $224.60 \pm 15.90$ \\
\hline$>\mathbf{8}$ & $\mathbf{3 5}$ & $267.83 \pm 29.95$ \\
\hline $\mathbf{p}$-value & & $<0.001$ \\
\hline
\end{tabular}

There was a statistically significant relation between the severity of NPDR and HbA1c level \% (Table 5).

Table (5): Comparison between stages of non-proliferative diabetic retinopathy (NPDR) according to HbA1c level \%

\begin{tabular}{|c|c|c|c|c|}
\hline HbA1c \% & $\begin{array}{c}\text { Mild } \\
\text { NPDR } \\
(\mathbf{n = 1 2})\end{array}$ & $\begin{array}{c}\text { Moderate } \\
\text { NPDR } \\
(\mathbf{n = 1 6})\end{array}$ & $\begin{array}{c}\text { Severe } \\
\text { NPDR } \\
(\mathbf{n = 2 2})\end{array}$ & \multirow{2}{*}{ p-value } \\
\cline { 1 - 4 } $7-8 \%(\mathrm{n}=15)$ & $9(75.0 \%)$ & $4(25.0 \%)$ & $2(9.1 \%)$ & \\
\cline { 1 - 3 } $8-9 \%(\mathrm{n}=13)$ & $2(16.7 \%)$ & $8(50.0 \%)$ & $3(13.6 \%)$ & \multirow{2}{*}{$<0.001$} \\
\cline { 1 - 3 } $9-10 \%(\mathrm{n}=12)$ & $1(8.3 \%)$ & $3(18.8 \%)$ & $8(36.4 \%)$ & \\
\cline { 1 - 4 } $10-11 \%(\mathrm{n}=10)$ & $0(0.0 \%)$ & $1(6.3 \%)$ & $9(40.9 \%)$ & \\
\hline
\end{tabular}

x2-Chi-square test

\section{DISCUSSION}

In our study the 2 groups of no diabetic retinopathy (DR) and non-proliferative diabetic retinopathy (NPDR) were comparable regarding age, and the mean age of the 2 groups was $>50$ years old.

In agreement with our study Yang et al. (2013) reported no association between age and DR. In contrast to our study, $A l$ Sarraf et al. (2010) reported a greater chance of diabetic retinopathy (DR) in individuals aged 50-59 years and $\geq 60$ years and Raman et al. (2012) also reported the significance of age as a risk factor for DR.

In our study, the 2 groups of no DR and NPDR were comparable regarding sex, but in group of no DR $(60 \%)$ patients were male and in NPDR group (52\%) patients were male. In agreement with our study Kajiwara et al. (2014) reported greater chance of DR among females. In contrast to our study, Raman et al. (2011) reported greater chance of DR among males. In our study the 2 groups were comparable regarding BCVA. It is interesting that, although increased macular thickness and volume were noted in patients with DR. The subgroups did not differ significantly in terms of VA. Some studies have shown that macular thickness is related to VA, but functionally significant loss of vision is less likely to occur when central subfield macular thickness is $<300 \mu \mathrm{m}$. All our patients had CST $<\quad 300 \mu \mathrm{m}$ and thus it is reasonable to assume that their VA had not been affected by macular changes at this stage (Sakata et al., 2011). 
Our study results showed that the mean duration of DM is longer in NPDR group than group of no DR. The total macular volume (TMV) was higher in the NPDR group than group of no DR. In contrast to our study, Yeung et al. (2010) reported that total macular volume is higher in diabetic patients without diabetic retinopathy than diabetic patients with non-proliferative diabetic retinopathy. In our study the average macular thickness and macular thickness of all of the 9 standard ETDRS subfields was higher in the NPDR group than group of no DR. In agreement with our study, Yeung et al. (2010) reported that central subfield macular thickness is higher in diabetic patients without diabetic retinopathy than diabetic patients with diabetic retinopathy.

In our study, the mean HbA1c level was significantly higher in the NPDR group than group of no DR. We found that the number of patients with $\mathrm{HbA} 1 \mathrm{c}$ level above $8.0 \%$ was significantly higher in the NPDR group than no DR group, while we found that the number of patients with HbA1c level lower than $8.0 \%$ was significantly higher in group of no DR than NPDR group, so we concluded that HbA1c level of $8.0 \%$ was a cut-off point for increased risk of diabetic retinopathy development. In our study we assessed the relation between the HbA1c level and central subfield macular thickness (CST) in both groups of no DR and NPDR separately. In the group of no DR, we found that there was significant association between $\mathrm{HbA1c}$ and CST.

Cho et al. (2020) reported that progression from no diabetic retinopathy in diabetic patients to NPDR stage was associated with higher HbAlc level.
Alabdulwahhab (2019) Reported that HbA1c level was significantly higher in patient with DR than patients without DR. In contrast to our study, Jiang et al. (2018) concluded that there's negative correlation between HbAlc level and central subfield macular thickness in diabetic patients without diabetic retinopathy.

In our study, we found significant association between CST and $\mathrm{HbAlc}$ level in the NPDR group. In agreement with our study Altintas et al. (2018) observed the change of both HbA1c level and central subfield macular thickness (CST) in diabetic patients with NPDR through follow-up visits; they found that there was a statistically significant correlation between $\mathrm{HbA} 1 \mathrm{c}$ and CST.

In another study, Subrayan et al. (2015) also reported that central subfield macular thickness was positively correlated with $\mathrm{HbA} 1 \mathrm{c}$ level. In contrast to our study, Asefzadeh et al. (2012) reported that there was no significant relation between retinal thickness and HbA1c level.

In our study, we found that incidence of DME was associated with increased HbA1c level and longer duration of DM. In agreement with our study, Klein et al. (2010) reported that the incidence of macular edema over the 10-year period was associated with higher levels of glycosylated hemoglobin and more severe retinopathy in both younger- and olderonset groups. Moreira et al. (2010) also reported that $\mathrm{HbA1c}$ was the only variable that showed a significant association with macular edema in diabetic retinopathy patients. 
In our study, results showed that the increase in the value of $\mathrm{HbAlc}$ level significantly affects the severity of diabetic retinopathy stages. Hence, it showed a highly significant positive correlation. In agreement with our study Meena et al. (2019) found positive significant correlation between $\mathrm{HbA1c}$ level and severity of diabetic retinopathy stages.

In our study, results showed that macular thickness in all of the 9 standard ETDRS subfields is positively correlated with the severity of diabetic retinopathy stages. In agreement with the present study, Browning and Fraser (2010) concluded that with increased retinopathy severity, the probability of macular thickening detected by OCT but not detected by clinical examination increased.

In our study, we divided both groups of no DR and NPDR into subgroups according to duration of DM and compared them regarding $\mathrm{HbAlc}$ level. We found that the no DR subgroups showed positive significant correlation between duration of $\mathrm{DM}$ and $\mathrm{HbA1c}$ level. We also found that the NPDR groups showed positive significant correlation between duration of DM and HbA1c level. In agreement with our study, de Waard et al. (2018) concluded that in both the radius and the tibia study population, participants with higher diabetes duration had a significantly higher HbA1c level than those with lower diabetes duration.

In the same study, in contrast to our study, de Waard et al. (2018) reported that microvascular disease subgroup showed no significant correlation between duration of diabetes and HbA1c level. In another study, Verma et al. (2010) reported that the results obtained indicated that the HbA1c levels showed a significant increase with the duration of diabetes.

HbA1c level was significantly lower in insulin using group than group of no insulin use. In agreement with our study Weitzman et al. (2010) found that there was significant inverse relation between HbA1c level and insulin intake in type 2 diabetic patients. In our study we found that insulin using diabetic patients had significantly lower risk of developing diabetic retinopathy than diabetic patients without insulin intake. In agreement with our study Shrote and Diagavane (2015) study showed an inverse association between the insulin intake and the presence of DR.

This study had some limitations. Firstly, the participants were all type 2 DM patients, and the results we discovered in this study might not apply to patients with type $1 \mathrm{DM}$. Secondly, we only observed the difference between the two groups at one point in time. Other changes may exist during the times we did not observe. Thirdly, our study didn't include follow up of patients that would provide us with more information about the effect of changes in HbAlc on macular thickness in the same studied diabetic patients when we follow them through months' interval visits.

\section{CONCLUSION}

Intensive glycemic control in type II diabetic patients might affect retinal vasculature and decrease ischemia, and affect the development and progression of non-proliferative diabetic retinopathy. 
Glycosylated hemoglobin of 8 or above increased the risk of incidence of DR and macular edema. Optical coherence tomography was a sensitive and noninvasive diagnostic tool in the evaluation of macular thickness.

\section{REFERENCES}

1. Alabdulwahhab K. (2019): Relationship between Diabetic Retinopathy and HbA1c in Type 2 Diabetics, Kingdom of Saudi Arabia. Journal of Research in Medical and Dental Science, 7: 1-5.

2. Al-Sarraf A, Al-Bannai S, Al-Furaih S and El-Shazly M (2010): Prevalence And Factors Associated With Diabetic Retinopathy, A Multi-Centric Study In Kuwait. Alexandria Journal of Medicine, 46: 99-108.

3. Altintas AG, Gulpamuk B, Cankurtaran V, Ilhan $C$ and Citirik M (2018): The Correlation between Changes in Biochemical Parameters and Central Macular Thickness in Patients with Non-Proliferative Diabetic Retinopathy. Medical Hypothesis, Discovery and Innovation in Ophthalmology, 7(1):10-16.

4. Asefzadeh B, Fisch BM, Parenteau CE and Cavallerano AA (2012): Macular thickness and systemic markers for diabetes in individuals with no or mild diabetic retinopathy. Clinical \& Experimental Ophthalmology, 36(5):455-63.

5. Browning DJ and Fraser CM (2010): Regional patterns of sight-threatening diabetic macular edema. Am. J. Ophthalmol., 140: 117124.

6. Cho A, Park HC, Lee YK, Shin YJ, Bae SH and Kim H (2020): Progression of Diabetic Retinopathy and Declining Renal Function in Patients with Type 2 Diabetes. Journal of Diabetes Research, 20: 36-45.

7. De Waard EA, de Jong JJ, Koster A, Savelberg HH, van Geel TA, Houben AJ, Schram MT, Dagnelie PC, van der Kallen CJ, Sep SJ and Stehouwer CD (2018): The association between diabetes status, $\mathrm{HbA1c}$, diabetes duration, microvascular disease, and bone quality of the distal radius and tibia as measured with high-resolution peripheral quantitative computed tomography-The Maastricht Study. Osteoporosis International, 29(12):2725-38.

8. Hee MR, Puliafito CA, Wong C, Duker JS, Reichel E and Rutledge B. (2010): Quantitative assessment of macular edema with optical coherence tomography. Arch Ophthalmol., 113: 1019-1029.

9. Hooper P, Boucher MC, Cruess A, Dawson KG, Delpero W, Greve M, Kozousek V, Lam WC and Maberley DA (2012): Canadian Ophthalmological Society evidencebased clinical practice guidelines for the management of diabetic retinopathy. Canadian Journal of Ophthalmology, 47 (2): 1-30.

10. Jiang S, Franco YL, Zhou Y and Chen J (2018): Nanotechnology in retinal drug delivery. International Journal of Ophthalmology, 11(6):1038-43.

11. Kajiwara A, Miyagawaa H, Saruwatari J, Kita A, Sakata $M$ and Kawata Y. (2014): Gender differences in the incidence and progression of diabetic retinopathy among Japanese patients with type 2 diabetes mellitus. Diabetes Res Clin Pract., 103: 7-10.

12. Klein R, Klein BE, Moss SE and Cruickshanks KJ (2010): The Wisconsin epidemiologic study of diabetic retinopathy $X V$. The long term incidence of macular edema. Ophthalmology, 102: 7-16.

13. Meena N, Meena HS and Meena MM (2019): Correlation of blood sugar and HBA1C levels in different stages of diabetic retinopathy at our tertiary care center in AJMER. International Journal of Scientific Research, 8: 216-222.

14. Moon SW, Kim HY, Kim SW, Oh J, Huh K and Oh IK (2011): The change of macular thickness measured by optical coherence tomography in relation to glycemic control in diabetic patients. Graefe's Arch Clin Exp Ophthalmol., 249(6): 839-848.

15. Moreira RO, Trujillo FR, Meirelles RM, Ellinger VC and Zagury L (2010): Use of optical coherence tomography (OCT) and indirect ophthalmoscopy in the diagnosis of macular edema in diabetic patients. Int Ophthalmol., 24: 331-336. 
16. Pierro L, Giatsidis SM, Mantovani E and Gagliardi M (2010): Macular thickness interoperator and intraoperator reproducibility in healthy eyes using 7 optical coherence tomography instruments. Am J Ophthalmol., 150: 199-204.

17. Raman R, Gupta A, Krishna S, Kulothungan $V$ and Sharma $T$ (2012): Prevalence and risk factors for diabetic microvascular complications in newly diagnosed type II diabetes mellitus. Sankara Nethralaya Diabetic Retinopathy Epidemiology and Molecular Genetic Study (SN-DREAMS, report 27). Journal of Diabetes and its Complications, 26: 123-128.

18. Raman R, Vaitheeswaran $K$, Vinita $K$ and Sharma T (2011): Is prevalence of retinopathy related to the age of onset of diabetes? Ophthlamic Res., 45: 36-41.

19. Sakata K, Funatsu H, Harino S, Noma H and Hori S (2011): Relationship of Macular Microcirculation and Retinal Thickness with Visual Acuity in Diabetic Macular Edema. Ophthalmology, 114: 2061-2069.

20.Shrote AP and DiAgAvAne $S$ (2015): Clinical evaluation of correlation between diabetic retinopathy with modifiable, nonmodifiable and other independent risk factors in tertiary set-up in central rural India. Journal of Clinical and Diagnostic Research, 9(10):1016.

21.Sohn EH, van Dijk HW, Jiao C, Kok PHB, Jeong W, Demirkaya N, Garmager A, Wit F, Kucukevcilioglu M, van Velthoven MEJ, DeVries JH, Mullins RF, Kuehn MH, Schlingemann RO, Sonka M, Verbraak FD and Abràmoff MD (2016): Retinal neurodegeneration may precede microvascular changes characteristic of diabetic retinopathy in diabetes mellitus. Proc Natl Acad Sci USA., 113: 2655-2664.

22. Subrayan V, Chang KM, Loo AV and Loke MF (2015): Proteomic Analysis of Saliva From Diabetic Patients in Different Stages of Diabetic Retinopathy. Investigative Ophthalmology \& Visual Science, 56(7):52026.

23. Verma $R$ (2010): Diabetic retinopathy: challenges and future directions. American Journal of Ophthalmology, 141(3):539-41.

24. Wani JS, Nasti AR, Ashai M, Keng M, Qureshi T and Rashid S (2010): Incidence of maculopathy in non-proliferative and proliferative diabetic retinopathy. JKPractitioner, 10: 275-278.

25. Weitzman S, Maislos M, Bodner-Fishman B and Rosen S (2010): Association of diabetic retinopathy, ischemic heart disease, and albuminuria with diabetic treatment in type 2 diabetic patients. Acta Diabetologica., 34(4):275-9.

26. Yang JY, Kim NK, Lee YJ, Noh JH, Kim DJ and Ko KS. (2013): Prevalence and factors associated with diabetic retinopathy in a Korean adult population. Diabetes Res Clin Pract., 102(3): 218-24.

27. Yeung L, Sun CC, Ku WC, Chuang LH, Chen CH and Huang BY. (2010): Associations between chronic glycosylated haemoglogin (HbA1c) level and macular volume in diabetes patients without macular oedema. Acta Ophthalmol., 88: 753-758. 


\section{تقييم سمك ماقولة الثبكية بإستخدام التصوير المقطعي

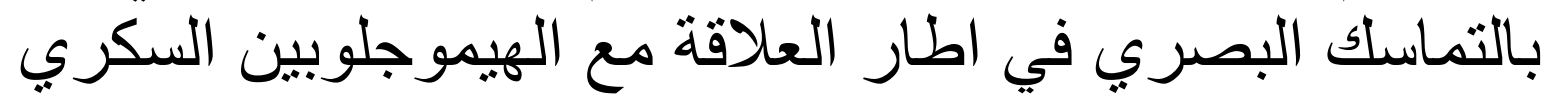

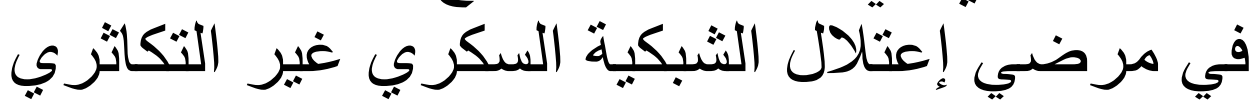
عمرو محمد بدر صلاح الدين, هاني محمود بيومي سمور, محمد الطاهر عبد الوهاب قسم طب وجر احة العيون, كلية الطب، جامعة الازهر

E-mail: $\underline{\text { dramrbadrsalah@ gmail.com }}$

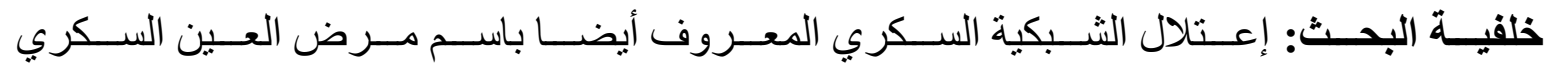

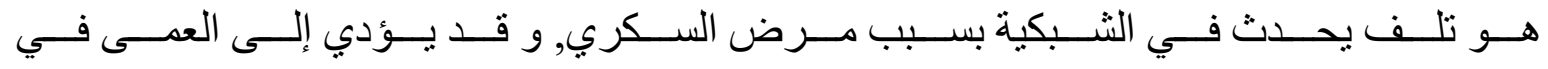
النهاية.

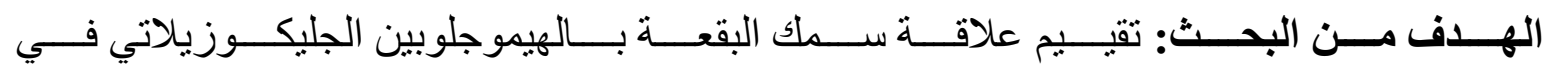
المرضى الذين يعانون من إعتلال الثبكية السكري غير التكاثري.

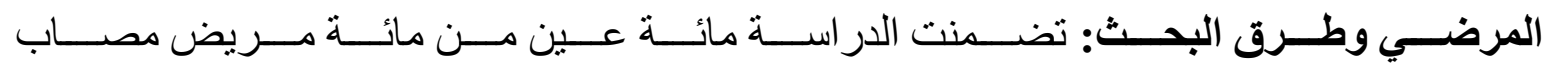

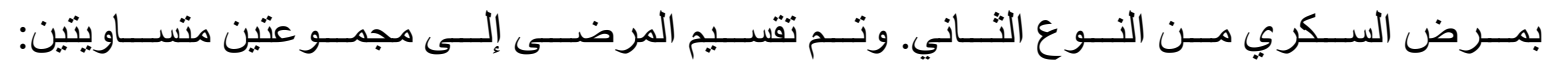

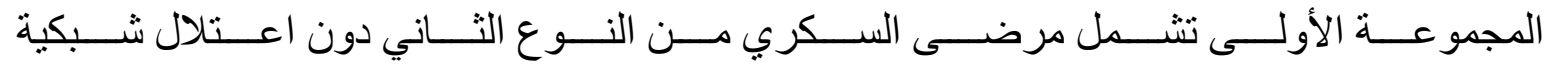

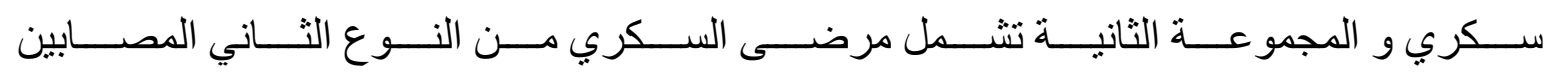
باعتلال الثبكية السكري غير التكاثري.

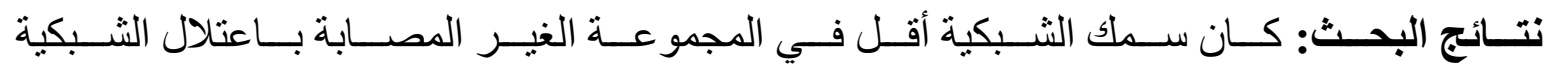

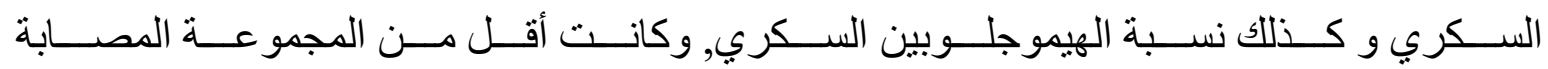

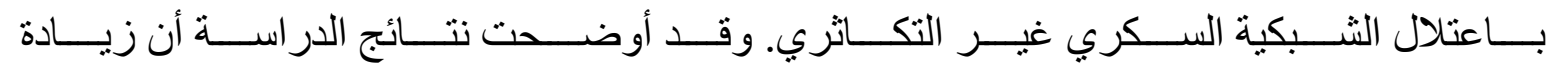

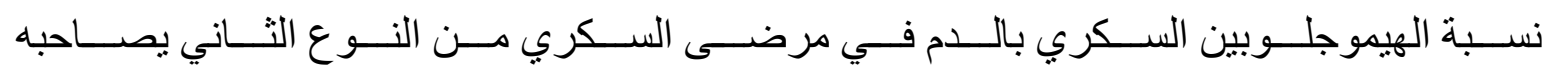

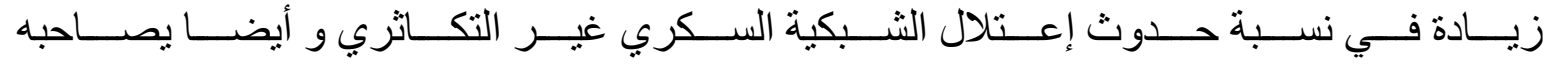

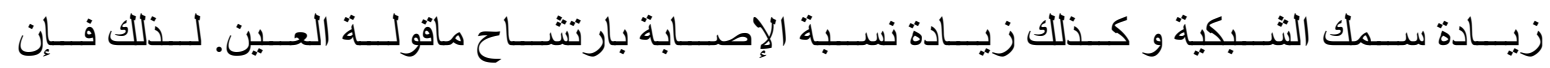

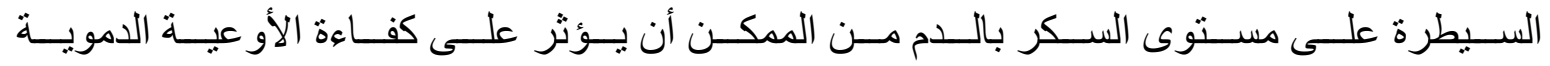

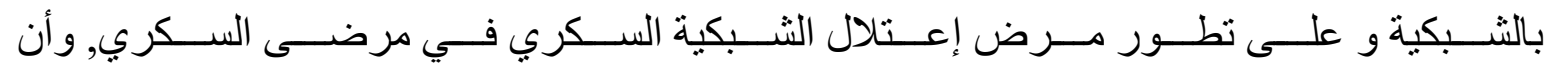

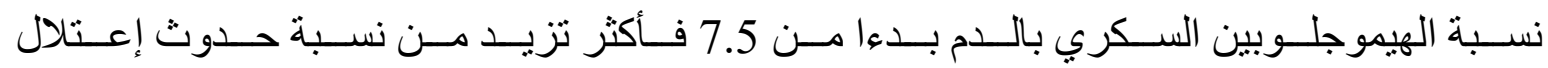




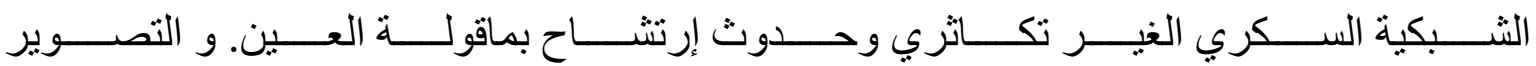
المقطعي البصري عامل رئيسي و آمن لقياس سمك الثبكية.

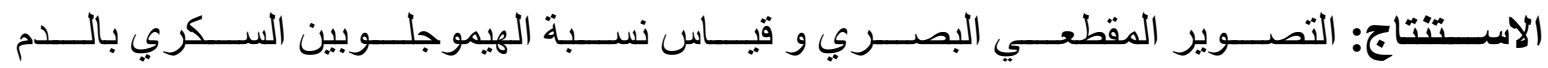

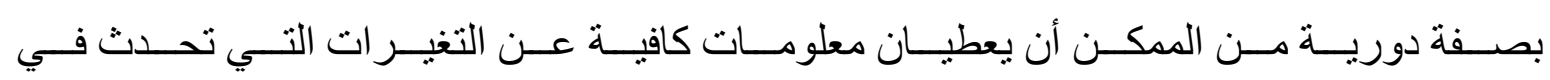
سمك الثبكية.

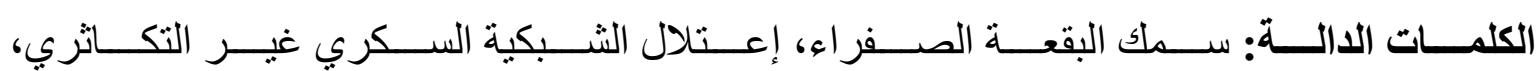
الهيموجلوبين الجليكوزيلاتي. 